\title{
Health care and social care costs of pneumonia in Denmark: a register-based study of all citizens and patients with COPD in three municipalities
}

This article was published in the following Dove Press journal:

International Journal of COPD

28 October 2015

Number of times this article has been viewed

\author{
Susanne Lausten Brogaard' \\ Maj Britt Dahl Nielsen' \\ Lars Ulrik Nielsen² \\ Trine Mosegaard Albretsen ${ }^{3}$ \\ Morten Bundgaard ${ }^{4}$ \\ Niels Anker' \\ Maja Appel' \\ Kim Gustavsen' \\ Rose-Marie Lindkvist ${ }^{5}$ \\ Anne Skjoldan ${ }^{2}$ \\ Grete Breinhild ${ }^{3}$ \\ Peter Bo Poulsen ${ }^{5}$ \\ 'COWI AS, Management - Health, \\ Kongens Lyngby, ${ }^{2}$ Seniors and Health \\ Department, Gladsaxe Municipality, \\ Welfare Technology, Søborg, ${ }^{3}$ Elderly \\ and Health Care Department, Lolland \\ Municipality, Maribo, ${ }^{4}$ Department of \\ Public Health, Holbaek Municipality, \\ Holbaek, ${ }^{5}$ Pfizer Denmark ApS, \\ Health \& Value, Ballerup, Denmark
}

Correspondence: Peter Bo Poulsen Pfizer Denmark ApS, Lautrupvang 8, DK-2750 Ballerup, Denmark

Tel +45 2920321 I

Fax +45 4420 I। I4

Email peterbo.poulsen@pfizer.com
Background: Pneumonia is a frequent lung infection and a serious illness, which is often diagnosed among patients hospitalized with acute exacerbations of COPD. The aim of this study was to estimate the attributable costs due to pneumonia among patients hospitalized with pneumonia compared to a matched general population control group without pneumonia hospitalization.

Methods: This study includes citizens older than 18 years from three municipalities ( $n=142,344)$. Based on national registers and municipal data, the health and social care costs of pneumonia in the second half of 2013 are estimated and compared with propensity score-matched population controls.

Results: The average health care costs of 383 patients hospitalized with pneumonia in the second half of 2013 were US\$34,561 per patient. Among pneumonia patients with COPD, the costs were US\$35,022. The attributable costs of patients with pneumonia compared to the population control group for the 6-month period were US\$24,155 per case. Overall, the attributable costs for the 383 pneumonia cases amounted to US\$9.25 million. Subgroup analyses showed that costs increased with age. The attributable costs due to pneumonia were highest among the 18-59-year-old and the 70-79-year-old patients. This difference is likely to reflect an increased risk of mortality among the pneumonia patients. Men have higher costs than women in the pneumonia group.

Conclusion: The costs of pneumonia are considerable. In three Danish municipalities, the attributable costs due to pneumonia were US\$24,155 per case or US\$64,992 per 1,000 inhabitants in the second half of 2013. Similar high health care and social care costs were found for pneumonia patients with COPD - the largest group having pneumonia episodes. The municipalities are responsible for $49 \%$ of the costs, while a closer focus on the prevention of pneumonia may be advisable, eg, starting with citizens having COPD.

Keywords: pneumonia, attributable costs, COPD, health care, social care, municipalities

\section{Introduction}

Pneumonia is a frequent lung infection and a serious illness. Community-acquired pneumonia (CAP) is the most common type of pneumonia caused by bacteria, virus, or fungi and is ranked as the fifth leading cause of mortality globally. ${ }^{1}$ The most common cause of bacterial pneumonia in adults is Streptococcus pneumoniae (pneumococcus) accounting for up to $30 \%$ of all pneumonia cases. ${ }^{1}$ Increasing with age and comorbidities, the overall incidence of CAP among adults is increasing, now ranging between 1.54 and 1.7 per 1,000 population in Europe. ${ }^{2}$

Pneumonia is often diagnosed among patients hospitalized with acute exacerbations of COPD. In Denmark, this association has been shown in $40 \%$ of all COPD admissions 
to the hospital. ${ }^{3}$ Benfield et al found that $44 \%$ of the cases of pneumococcal pneumonia were among patients with COPD. ${ }^{4}$ The group of chronically ill patients having COPD is therefore the largest risk group for pneumococcal pneumonia.

Treatment depends on the type of pneumonia and the severity of symptoms, but up to $80 \%$ of pneumonia episodes are treated in the primary care..$^{5}$ Hospitalization might be required if symptoms are especially serious or if the patient has a weakened immune system or other serious illnesses. The annual rate of hospitalization due to pneumonia in Denmark is 40,000 (approximately eight per 1,000 citizens). ${ }^{3,6}$ In recent years, the rate of hospitalization for pneumonia has increased in Denmark, and this trend is generally seen in other developed countries. ${ }^{6,7}$ This increase is likely to continue due to the fast aging of the population, doubling the demand for health care in coming decades and leading to pneumonia to consume a much larger share of the health resources in the future. ${ }^{2,3,6,8}$ As with COPD, which is among the most costly diseases and one of the largest chronic disease groups in the Western world, ${ }^{9}$ the economic burden of pneumonia, including CAP, is therefore significant.

In Europe, previous studies have assessed that costs due to pneumonia was $\sim € 10.1$ billion annually. ${ }^{10}$ A number of European studies from countries such as Germany, Spain, Italy, and Romania have investigated the economic consequences of pneumonia, including CAP. ${ }^{11-15}$ Some of these studies are based on prospective designs, while others are retrospective utilizing registries, and some include a control group without pneumonia, while others do not. However, most importantly none of the studies includes a broader perspective than the direct health care costs. Moreover, no studies have to date estimated the costs of pneumonia in Denmark.

Utilizing the national registries and local municipality administrative data, the purpose of the present study is to estimate the attributable costs due to pneumonia in hospitalized patients over a 6-month period in three Danish municipalities covering 142,344 (older than 18 years) citizens in total $(3 \%$ of the Danish population). Furthermore, the attributable costs due to pneumonia according to the different administrative and budgetary levels (national, regional, municipality, and patient) are estimated, as well as for different subgroups such as patients with COPD, for men versus women, and for different age groups.

\section{Materials and methods}

\section{Study design}

A register-based cost-of-illness analysis of the attributable costs due to pneumonia in 2013 was performed among citizens older than 18 years in three average-sized Danish municipalities
(Gladsaxe, Holbaek, and Lolland). The total study population consisted of 142,344 citizens. Based on the newest data, cases comprised patients hospitalized with pneumonia as primary diagnosis during the second half of 2013 (July 1, 2013 to December 31, 2013) - with no prior pneumonia hospitalization during the first half of 2013 (January 1, 2013 to June 30, 2013; washout period). The potential control group consisted of citizens not hospitalized with pneumonia in 2013. The number of hospitalizations due to pneumonia in 2013 did not differ from previous years, besides that pneumonia hospitalization rates have been shown to continuously increase, largely driven by recurrent pneumonia episodes in elderly patients and secondary diagnoses, eg, $40 \%$ of hospitalizations for exacerbation of COPD in Denmark are associated with pneumonia. ${ }^{16}$ However, by covering only the second half of 2013, some of the important winter months have been omitted, whereas cases appearing in January and February are not included in the analysis. This seasonal variation related to changes in the temperature has previously been documented for pneumococcal bacteremia, where changes in temperature predict peaks in the incidence. ${ }^{17}$ Omitting some of the coldest months may then result in a conservative estimate of the true costs of illness related to pneumonia.

\section{The Danish health care system}

Access to a wide range of health services is largely free of charge for all citizens in Denmark. The health care system is organized according to three administrative levels: national, regional, and local (municipalities). The regional level is responsible for providing hospital care and finances general practitioners (GPs), specialists, physiotherapists, dentist, and prescription medicine. The municipalities are responsible for disease prevention, health promotion, rehabilitation, nursing homes, home nurses, assistive devices, etc. Furthermore, the municipalities pay part of the costs of the regional health care services, eg, $34 \%$ of the costs of having citizens hospitalized up to a maximum of US\$2,532 per year (2013 rules). There are relatively few out-of-pocket expenses for the citizens, which applies for a share of dental care for citizens older than 18 years and copayment for prescription medicines in the primary health care sector as the largest groups. Moreover, complimentary private health insurance reimburses part of outof-pocket expenses of pharmaceuticals and dental care. ${ }^{18}$

\section{Data sources}

Every Danish citizen has their own unique personal identification code, which is the case in the Nordic countries only. In Denmark, national registries covering all health care activities related to specific disease based on International 
Classification of Diseases, tenth edition and social transfer payments exist. Having a research access to the national registries, in the present study, the data from these registries, using the citizens' personal identification codes, were combined with data from the local municipality level on the specific social care services given. This approach made it possible to estimate the costs of health care and social care of pneumonia.

The data included on health care cost and health care utilization came from three national health registries (the Danish National Patient Register, the Danish National Health Services Register, and the National Prescription Registry), the Danish Register for Evaluation of Marginalization (DREAM) as well as data from the three municipalities.

The Danish National Patient register comprises inpatient admissions and outpatient admissions within hospitals based on International Classification of Diseases, tenth edition codes. All hospital services are assigned a tariff from the system of diagnosis-related groups (DRGs). The Danish National Health Services Register covers contacts with GPs and all practicing specialists, such as dentistry and physiotherapy. The register also includes the charge of these contacts. Finally, the National Prescription Registry includes the Anatomical Therapeutic Chemical Classification Code, the total price of the drug, and the share paid by the public health care authorities. Although costs in the health care sector are well described in the national registers, other social care costs, for instance, for rehabilitation, are not covered in the national registers. ${ }^{18}$ Data on social care costs were therefore retrieved from administrative records in the three municipalities, including referral to practical help or personal care (number of hours), home health care (hours), and use of nursing home/care center (days).

Moreover, to assess productivity losses, data on social transfer payments came from the Danish Register for Evaluation of Marginalization (DREAM) that includes information on public transfer payments administered by Danish ministries, municipalities, and Statistics Denmark for all Danish citizens on a weekly basis. ${ }^{19}$

Baseline data on sociodemographical characteristics of the study population are age, sex, country of origin, level of education, residence (municipality), marital status, income, employment status, disability and registration of sickness absence, and different types of unemployment came from Statistics Denmark and DREAM. Moreover, data on baseline health characteristics (previous history of health care utilization during the first part of 2013) such as average length of stay during hospitalization, number of inpatient and outpatient services, number of services from GP, and a previous history of COPD and congestive heart failure (CHF) were included as well. COPD or CHF was measured as inpatient or outpatient care with COPD or CHF as the primary or secondary diagnosis or prescription medication for obstructive airway diseases during the first part of 2013.

\section{Analyses}

To calculate the attributable cost due to pneumonia, a propensity score matching approach was used to construct a sociodemographic and health-matched control group without pneumonia. First, in a logistic regression model, the baseline characteristics that predicted hospitalization with pneumonia in the entire study population were identified. Next, the propensity scores were generated by estimating the conditional probability of hospitalization with pneumonia in a multivariable logistic regression model including the following covariates: age, sex, income, early retirement, average length of stay during hospitalization, number of outpatient visits, number of GP services, and a history of COPD and CHF.

From the potential control subjects, five controls for each participant were selected using nearest neighbor matching (with replacement) with a caliper of 0.0014 (based on a standard deviation of 0.20 of the probability of being hospitalized with pneumonia). Six cases were excluded, because no control subject was available within this range. The STATA (Version 13.1) program and the SAS program (Version 9.3) were used for the statistical analyses. The study was approved by the Danish Data Protection Agency (j.nr. 2006-41-6811). Approval from an ethics committee, nor patients consent, was not required by Danish law, as the study was based on register data only.

\section{Results}

In 2013, 1,137 citizens were hospitalized with pneumonia in the three municipalities (325 in Lolland, 374 in Gladsaxe, and 438 in Holbæk). Among these, 383 pneumonia cases were identified and included in the second half of 2013. Table 1 shows that $63 \%$ of the patients were older than 70 years, and the majority were old-age pensioners (72\%). The vast majority $(93 \%)$ of patients had utilized services from their GP, and $66 \%$ had one or more outpatient visits. Nine percent of the cases were treated for COPD, defined as prescribed medication or health care visit due to COPD during the first half of 2013. The percentage of patients with COPD increased to $21 \%$ at the end of 2013 , indicating high comorbidity.

Due to the matching procedure, which allows for replacement, the same control subject could be matched with several cases. Thus, in total, the control group consisted of 1,231 
Table I Baseline characteristics of PA patients and the control group (the first half of $2013, \%$ )

\begin{tabular}{|c|c|c|}
\hline Characteristics & $\begin{array}{l}\text { Disease group } \\
(n=383 ; \%)\end{array}$ & $\begin{array}{l}\text { Control group } \\
(\mathrm{n}=1,231 ; \mathrm{;} \%)\end{array}$ \\
\hline \multicolumn{3}{|l|}{$\mathrm{Sex}^{\mathrm{b}}$} \\
\hline Men & 51 & 50 \\
\hline Women & 49 & 50 \\
\hline \multicolumn{3}{|l|}{ Age (years) b } \\
\hline $18-29$ & I & I \\
\hline $30-39$ & 3 & 2 \\
\hline $40-49$ & 5 & 5 \\
\hline $50-59$ & 10 & 9 \\
\hline $60-69$ & 19 & 19 \\
\hline 70-79 & 30 & 29 \\
\hline $80+$ & 33 & 34 \\
\hline \multicolumn{3}{|l|}{ Municipality } \\
\hline Gladsaxe & 28 & 35 \\
\hline Holbaek & 42 & 34 \\
\hline Lolland & 30 & 31 \\
\hline \multicolumn{3}{|l|}{ Employment } \\
\hline Employed & 14 & 15 \\
\hline Unemployed & 1 & 1 \\
\hline Retirement, pension, etc & 86 & 84 \\
\hline Retirement & 72 & 62 \\
\hline Early retirement ${ }^{\mathrm{b}}$ & 12 & 11 \\
\hline \multicolumn{3}{|l|}{ Income, DKK ${ }^{\mathrm{b}}$} \\
\hline$<100,000$ & 2 & 2 \\
\hline $100,000-200,000$ & 65 & 64 \\
\hline $200,000-300,000$ & 19 & 20 \\
\hline $300,000-400,000$ & 7 & 7 \\
\hline 400,000 & 7 & 7 \\
\hline \multicolumn{3}{|c|}{ Average length of stay during hospitalization, days ${ }^{\mathrm{b}}$} \\
\hline 0 & 64 & 66 \\
\hline$<2$ & 13 & 12 \\
\hline$<3$ & 6 & 5 \\
\hline$<5$ & 5 & 5 \\
\hline+5 & 12 & 11 \\
\hline \multicolumn{3}{|l|}{ Number of outpatient visits ${ }^{b}$} \\
\hline 0 & 34 & 34 \\
\hline 1 & 14 & 15 \\
\hline $2-6$ & 35 & 35 \\
\hline $7+$ & 17 & 16 \\
\hline \multicolumn{3}{|l|}{ Number of visits, GPb } \\
\hline 0 & 7 & 7 \\
\hline $1-5$ & 23 & 23 \\
\hline $6+$ & 70 & 70 \\
\hline $\mathrm{COPD}^{\mathrm{b}}$ & 9 & 9 \\
\hline Coronary heart failure $^{\mathrm{b}}$ & 2 & I \\
\hline
\end{tabular}

Notes: Statistical testing (Student $t$-test $P \leq 0.05$ ) showed that none of these covariates were significantly different between the disease group and the control group. ${ }^{\text {aFor }}$ the control group, we present the weighted percentage. ${ }^{b}$ Covariates used in the propensity score matching. "Retirement, pension, etc," is covering all citizens outside workforce. "Retirement" is only those retired from the workforce due to age. "Early retirement" is those retired prior to the age of 65, where people normally retire in Denmark. Early retirement is often due to disease.

Abbreviations: GP, general practitioner; PA, pneumonia; DKK, Danish Kroner.

subjects without pneumonia in 2013. There are no major differences between the control group and the pneumonia cases.

Table 2 shows the total mean health care and social care costs in the disease group having pneumonia and in the control group without pneumonia. Besides the pneumonia diagnosed in the disease group, both groups of patients have been hospitalized for other reasons (second half of 2013) such as treatment of heart diseases, diseases in the digestive system and neoplasm, and other diseases of the respiratory system such as COPD and respiratory failure. The mean attributable health care and social care costs due to pneumonia during the second half of 2013 were US\$24,155 per average patient for a six month period irrespective of whether the subject survived or not. With 383 pneumonia cases in the three municipalities during 6 months, these attributable costs due to pneumonia amounted US\$92.5 million or US\$64,992 per 1,000 inhabitants.

Moreover, the Table 2 shows that these costs fall on the regional level with US\$12,311 corresponding to $51 \%$ of total attributable costs and on the local municipalities with US $\$ 11,767$ corresponding to $49 \%$. None of the costs included in this study fall on the national level (eg sickness-absence benefits and different types of unemployment benefits) and only US\$77 $(<1 \%)$ fall on the patient.

Table 3 shows the mean costs for different subgroups of patients during the second half of 2013. The table shows that the costs among pneumonia patients with COPD in 2013 were US\$35,022 compared to US\$34,437 among patients without COPD (difference: US\$585). The difference increases when looking at a COPD control group without pneumonia. The costs of patients with COPD in the control group were US\$15,716 compared to US\$9,636 without COPD (difference: US\$6,080). This means that the attributable costs due to pneumonia for a patient with COPD are $=\mathrm{US} \$ 19,306$.

Sex differences are seen between men and women in the control group (men: US\$9,797; women: US\$11,036) and among the pneumonia patients (men: US\$38,513; women: US\$30,505). Among pneumonia patients, men are more expensive than women, whereas the opposite is the case in the control group. Moreover, the table shows that the average costs increase with age. In the control group, the highest costs accrue to the age group older than 80 years. Among the pneumonia patients, the highest costs accrue to the age groups 70-79 years and older than 80 years. However, the attributable costs due to pneumonia are highest in the age groups 18-59 years and 70-79 years and nearly as high in the age group 60-69 years.

At the end of 2013,23\% of the pneumonia cases had died compared to $3 \%$ among the control. This may indicate the severity of pneumonia, although data on death cause were not available.

\section{Discussion}

The combination of national registries and local data from the municipalities is a strength of the present study. Moreover, 
Table 2 Mean health care and social care costs per average patient (USD) ${ }^{\mathrm{a}}$

\begin{tabular}{|c|c|c|c|c|c|}
\hline & \multicolumn{2}{|c|}{ Disease group } & \multicolumn{2}{|l|}{ Controls } & \multirow{2}{*}{$\begin{array}{l}\text { Attributable costs due to } \\
\text { pneumonia, mean difference } \\
\text { per average patient }\end{array}$} \\
\hline & No patients & $\begin{array}{l}\text { Mean costs per } \\
\text { average patient }\end{array}$ & No patients & $\begin{array}{l}\text { Mean costs per } \\
\text { average patient }\end{array}$ & \\
\hline Mean costs, first half of 2013 & 383 & 21,873 & $1,23 \mid$ & $|2,97|$ & \\
\hline Mean costs, second half of 2013 & 383 & 34,561 & $|, 23|$ & 10,406 & 24,155 \\
\hline Mean costs, 2013 & 383 & 56,434 & $|, 23|$ & 23,377 & \\
\hline \multicolumn{6}{|l|}{ Mean cost during 2013 by payer } \\
\hline National level & 383 & 0 & $|, 23|$ & 0 & \\
\hline Regional level & 383 & 24,000 & $|, 23|$ & 10,795 & \\
\hline Municipality level ${ }^{\mathrm{b}}$ & 383 & 32,006 & $|, 23|$ & 12,237 & \\
\hline Patient level ${ }^{c}$ & 383 & 429 & $|, 23|$ & 345 & \\
\hline \multicolumn{6}{|l|}{ Mean costs, second half of 2013} \\
\hline National level & 383 & 0 & $|, 23|$ & 0 & 0 \\
\hline Regional level & 383 & 16,728 & $|, 23|$ & 4,418 & $|2,3| \mid$ \\
\hline Municipality level ${ }^{\mathrm{a}}$ & 383 & 17,599 & 1,231 & 5,832 & 11,767 \\
\hline Patient level ${ }^{c}$ & 383 & 234 & $\mathrm{I}, 23 \mathrm{I}$ & 157 & 77 \\
\hline
\end{tabular}

Notes: ${ }^{\text {T}}$ The annual average exchange rate for USD in 2013 from the Central Bank of Denmark has been used to exchange from DKK to USD. 'The costs on the local municipality level consists of the municipalities cofinancing of regional health services and the municipalities' own health care and social care. The costs of the municipalities' own health care and social care are equally divided between the first and second parts of 2013 , as it was not possible to allocate the costs exactly between the first and second half of 2013. Includes out-of-pocket spending for prescription medicine and health insurance.

Abbreviations: DKK, Danish Krone; USD, United States dollar.

data from municipal records on social care costs such as practical assistance, personal care, home health care, and use of nursing home/care center were identified allowing the inclusion of a wide range of social care costs associated with pneumonia.

In the study, the attributable costs of inpatient pneumonia among citizens, older than 18 years, in three Danish Municipalities were estimated. These attributable costs due to pneumonia amounted to be US\$24,155 during a period of 6 months following the incident pneumonia case. Overall for all 383 cases in the three municipalities during 6 months, the total attributable costs were at a level of US\$9.25 million. Thus, the findings show high health care and social care costs associated with pneumonia hospitalizations - especially for the regional and the local municipality levels. Although it is difficult to compare findings directly with other studies, because of differences in settings, methods, and health care systems, our findings corroborate previous estimates showing that pneumonia is a costly disease. For instance, Thomas et al found that the total medical costs for patients during and 1 year following a pneumonia hospitalization were US\$15,682 higher than matched control patients without pneumonia. $^{20}$

For the group of patients with COPD, the average health care and social care costs during 6 months were estimated to be US\$35,022 (Table 3). This was almost at the same level as for non-COPD pneumonia cases (US\$34,437, Table 3) and all pneumonia cases (US\$34,561, Table 3). However, the similar costs in the control group of nonpneumonia patients with COPD were higher than for nonpneumonia cases without

Table 3 Subgroup analyses of mean health care and social care costs per average patient in the second half of 2013 (USD) ${ }^{\mathrm{a}}$

\begin{tabular}{|c|c|c|c|c|c|}
\hline & \multicolumn{2}{|c|}{ Disease group } & \multicolumn{2}{|l|}{ Controls } & \multirow{2}{*}{$\begin{array}{l}\text { Attributable costs due to } \\
\text { pneumonia, mean difference } \\
\text { per average patient }\end{array}$} \\
\hline & $\begin{array}{l}\text { No } \\
\text { patients }\end{array}$ & $\begin{array}{l}\text { Mean costs per average } \\
\text { patient, second half of } 2013\end{array}$ & $\begin{array}{l}\text { No } \\
\text { patients }\end{array}$ & $\begin{array}{l}\text { Mean costs per average } \\
\text { patient, second half of } 2013\end{array}$ & \\
\hline \multicolumn{6}{|l|}{ COPD } \\
\hline Yes & 81 & 35,022 & 156 & 15,716 & 19,306 \\
\hline No & 302 & 34,437 & $\mathrm{I}, 075$ & 9,636 & 24,802 \\
\hline \multicolumn{6}{|l|}{ Age (years) } \\
\hline $18-59$ & 72 & 31,888 & 311 & 5,896 & 25,992 \\
\hline $60-69$ & 72 & 30,558 & 293 & 6,322 & 24,237 \\
\hline $70-79$ & 114 & 37,464 & 312 & $|I, 31|$ & 26,153 \\
\hline $80+$ & 125 & 35,759 & 315 & 17,762 & 17,996 \\
\hline \multicolumn{6}{|l|}{ Sex } \\
\hline Men & 194 & 38,513 & 626 & 9,797 & 28,715 \\
\hline Women & 189 & 30,505 & 605 & 11,036 & 19,468 \\
\hline
\end{tabular}

Note: ${ }^{\text {TT }}$ The annual average exchange rate for USD in 2013 from the Central Bank of Denmark has been used to exchange from DKK to USD. Abbreviations: DKK, Danish Krone; USD, United States dollar. 
COPD as well as all nonpneumonia cases (US\$15,716 versus US\$10,406 or US\$9,636). The reason for this is most likely that the nonpneumonia COPD control group has a higher degree of morbidity due to their COPD condition, eg, exacerbations, compared with both all nonpneumonia cases and the non-COPD control group. It has been shown that $40 \%$ of patients with COPD hospitalized with exacerbation also have comorbid pneumonia. ${ }^{16}$ This means that $60 \%$ of the patients with COPD hospitalized with exacerbations without pneumonia-associated episodes may explain part of the higher costs in the nonpneumonia COPD control group. Furthermore, the rate of comorbidities in a chronic disease group like COPD is higher than among patients without chronic disease. With a more diseased nonpneumonia COPD control group being more expensive compared with those controls without COPD and all controls, it then follows that the attributable costs of pneumonia for a patient with COPD also will be lower (US\$19,306) compared with all cases and those without COPD.

In the study, $19 \%$ of the pneumonia patients were under the age of 59 years, of whom a proportion are still active in the workforce. This might imply a considerable economic burden in terms of productivity losses in this group. However, the ability to estimate the productivity losses was hampered by the sample size (see "Study limitations" section). Moreover, the majority of the pneumonia patients were older than the age of $70(63 \%)$ and only 14\% were employed at baseline. Thus, health care and social care costs are likely to make up the largest proportion of costs in these older than 70 years of age group in the three municipalities. In Europe, Welte et al found that pneumonia costs $€ 5.7$ billion annually, with inpatient care accounting for $€ 5.0$ billion, outpatient care for $€ 0.5$ billion, and drugs $€ 0.2$ billion. ${ }^{6}$ In comparison, indirect productivity losses amounted to $€ 3.6$ billion. $^{6}$

\section{Study limitations}

The present study has some limitations. First, since propensity scores are estimated using measured data, they cannot account for unmeasured or imperfectly measured variables and with data for 6 months only, which might lead to imprecisions in the matching procedure. Therefore, residual systematic bias cannot be excluded. Moreover, it was not possible to use data from municipal records to identify baseline characteristics that predicted hospitalization with pneumonia. This was due to the fact that the local data were only available for the entire year of 2013 leaving no possibility to distinguish between the prediction and the impact of pneumonia. The data from municipal records are therefore used only for the calculation of costs with the assumption that they can be equally distributed between the first and second half of 2013. These circumstances may explain the difference seen in costs between the disease and the control group in the first half of 2013 (Table 2).

Second, only cases hospitalized with pneumonia were included. However, up to $80 \%$ of pneumonia episodes are treated in primary care. Costs related to these episodes were therefore not included in the estimates in this study. Moreover, the attributable costs estimated were only for a 6-month period. While Thomas et al found that the attributable costs due to pneumonia mainly accrue immediately after hospitalization, another study has shown that the attributable costs due to pneumonia in older adults with COPD extend up to 24 months after hospitalization. ${ }^{20,21}$ In this regard, it should also be noted that not all potential costs were included. For instance, the local municipalities record health care costs differently and only activities for which comparable costs data could be retrieved were included. Moreover, productivity costs were not included in the costs estimate, partly because only a low percentage of the pneumonia patients were still employed at the time of their hospitalization. Therefore, the estimate of the attributable costs due to pneumonia mostly be regarded as an underestimate of the actual attributable costs due to pneumonia in Denmark.

\section{Conclusion}

With the aging populations, the costs of pneumonia are likely to increase over time. As a large part of the pneumonia cases are preventable, this study may provide useful evidence for the national, regional, and local municipality levels and for health care providers on the benefit of investing further in the prevention and treatment of pneumonia. The results of the study imply that the budgets of the average Danish municipality (with 50,000 older than 18 years inhabitants) like the three municipalities are affected with around half (49\%) of the total attributable cost due to pneumonia of US\$3.1 million for a 6-month period - a figure that will be larger covering a whole year. Focusing solely on patients with COPD being a group with a high frequency of pneumonia episodes, the same picture arrives, although with a bit lower attributable costs due to high costs in the COPD control group. Danish municipalities and other similar local authorities in comparable countries may therefore have a closer attention to pneumonia of their citizens, eg, starting in COPD, and its future prevention.

\section{Author contributions}

Susanne Lausten Brogaard and Maj Britt Dahl Nielsen contributed to the acquisition of data, statistical analyses, 
interpretation of results, and drafting of the manuscript. Lars Ulrik Nielsen, Trine Mosegaard Albretsen, Morten Bundgaard, Anne Skjoldan, and Grete Breinhild contributed to the study design, acquisition of data, and revision of the manuscript. Niels Anker and Maja Appel contributed to the acquisition of data, statistical analyses, interpretation of results, and revision of the manuscript. Kim Gustavsen, Rose-Marie Lindkvist, and Peter Bo Poulsen contributed to the conception and design of the study, interpretation of results, and revision of the manuscript. All authors approved the final version to be published and agree to be accountable for all aspects of the work.

\section{Disclosure}

Pfizer Denmark ApS funded COWI as the technical vendor of the project. The municipalities did not receive any funding from Pfizer and paid for their own participation and work in the project. The authors report no other conflicts of interest in this work.

\section{References}

1. Niederman MS, Luna M. Community-acquired pneumonia guidelines: a global perspective. Semin Respir Crit Care Med. 2012;33: 298-310.

2. Torres A, Peetermans WE, Viegi G, Blasi F. Risk factors for communityacquired pnemonia in adults in Europe: a literature review. Thorax. 2013;68:10571065.

3. Soegaard M, Nielsen RB, Schønheyder HC, Nørgaard M, Thomsen RW. Nationwide trends in pneumonia hospitalization rates and mortality, Denmark 1997-2011. Resp Med. 2014;108:1214-1222.

4. Benfield T, Skovgaard M, Schønheyder HC, et al. Serotype distribution in non-bacteremic pneumococcal pneumonia: association with disease severity and implications for pneumococcal conjugate vaccines. PLoS One. 2013;8:e72743.

5. Hoare Z, Lim WS. Pneumonia: update on diagnosis and management. BMJ. 2006;332:1077-1079.

6. Welte T, Torres A, Nathwani D. Clinical and economic burden of community-aquired pneumonia among adults in Europe. Thorax. 2010; 67(1):71-79.
7. Statistics Denmark. Flere indlæggelser med lungebetændelse Sygehusbenyttelse 2011 (Increase in hospitalizations with pneumonia. Hospital utilization). Stat Den. 2012;506:5.

8. Wroe PC, Finkelstein JA, Ray T, Linder JA, Johnson KM, Huang SS. Aging population and furture burden of pnemoccocal pneumonia in the United States. J Infect Dis. 2012;205:1589-1592.

9. Barnes J. Chronic obstructive pulmonary disease. $N$ Engl J Med. 2000;343(4):269-280.

10. The economic burden of lung disease. In: European Lung White Book. 2nd ed. European Respiratory Society/European Lung Foundation; 2003:55-65.

11. Bartolomé M, Almirall J, Morera J, et al; Marseme CommunityAquired Pneumonia Study Group. A population-based study on the cost of care for community-acquired pneumonia. Eur Respir J. 2004;23: 610-616.

12. Monge V, San-Martín M, González A. The burden of community-acquired pneumonia in Spain. Eur J Public Health. 2001;11:362-364.

13. Negro RD, Berto P, Tognella P, Quareni L; Global Outcomes in Lung Disease Study Group. Cost-of-illness of lung disease in the TricVeneto Region, Italy: the GOLD study. Monaldi Arch Chest Dis. 2002; 57:3-9.

14. Bauer TT, Welte T, Ernen C, et al. Cost analyses of communityacquired pneumonia from the hospital perspective. Chest. 2005;128(4): $2238-2246$.

15. Stoicescu I, Mihaescu T, Azoicai T, Balca I. Preliminary assesment of streptococccus pneumoniae, pneumonia, economic and clinical burden in Romania. Pneumonologica. 2007;56(3):118-123.

16. Søgaard M, Nielsen RB, Schønheyder HC, Nørgaard M, Thomsen RW. Nationwide trends in pneumonia hospitalization rates and mortality, Denmark 1997-2011. Respir Med. 2014;108(8):1214-1222.

17. Tvedebrink T, Lundbye-Christensen S, Thomsen RW, Dethlefsen C, Schønheyder HC. Seasonal changes in climatic parameters and their relationship with the incidence of pneumococcal bacteraemia in Denmark. Clin Microbiol Infect. 2008;14(12):1183-1186.

18. Kruse M, Christiansen T. Register-based studies of healthcare costs. Scand J Public Health. 2011;39(7):206-209.

19. Hjollund HN, Larsen FB, Andersen JH. Register-based follow-up of social benefits and other transfer payments: accuracy and degree of completeness in a Danish interdepartmental administrative database compared with a population-based survey. Scand J Public Health. 2007; 35(5):497-502.

20. Thomas CP, Ryan M, Chapman JD, et al. Incidence and cost of pnemonia in Medicare Beneficiaries. Chest Infect. 2012;142(4): 973-981.

21. Ryan M, Suaya JA, Chapman JD, Stason WB, Shepard DS, Thomas CP. Incidence and costs of pneumonia in older adults with COPD in the United States. PLoS One. 2013;8(10):e75887.
International Journal of COPD

\section{Publish your work in this journal}

The International Journal of COPD is an international, peer-reviewed journal of therapeutics and pharmacology focusing on concise rapid reporting of clinical studies and reviews in COPD. Special focus is given to the pathophysiological processes underlying the disease, intervention programs, patient focused education, and self management protocols.

\section{Dovepress}

This journal is indexed on PubMed Central, MedLine and CAS. The manuscript management system is completely online and includes a very quick and fair peer-review system, which is all easy to use. Visit http://www.dovepress.com/testimonials.php to read real quotes from published authors. 